de Justiça, que dando provimento á appellação, mandará proseguir, desobstruida do injuridico e fálso incidente chamado de attentado, a causa principal. Sem duvida mais tarde, n'este sanctuario do direito, virá o Appellante receber a palavra definitiva da justiça, que os senhores feudaes do Rio Claro lhe estão systematica e terroristamente negando.

E. S.

O Advogado

Dr. João Pereira Monteiro.

São Paulo, I. $^{\circ}$ de Feverevro de 1892.

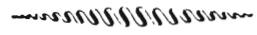 \\ PHILOSOPHIA DO DIREITO
}

\section{A THEORIA DE IHERING}

No seu livro, Le Droit Pur, Edmond Picard classifica Ihering entre os jurisconsultos philosophos que applicam o methodo positivo ao estudo dos principios do direito. Antes e depois da publicação da obra do jurista belga, que pretende haver produzido um livro original, porque usou de formas novas para exprimir idéas velhas, não têm faltado cultores do direito que suppõem scientifica a escóla do eminente professor de Goettingen.

A recente traduç̧ão por Meulenaere da primeira parte da theoria de lhering sobre o direito e a moral, facilitando entre nós o conhecimento de um systema de que antes se tinha noticia unicamente pelos vulgarisadores, taes como Aguiléra, Tanon, Bouglé e outros, 
imprime um certo cunho de opportunidade a esta exposição synthetica e breve critica da escóla do eximio jurisconsulto.

$$
* * *
$$

Como quasi todos os organisadores de systemas no dominio do direito, Ihering apoia a sua doutrina em um principio fundamental de ordem philosophica. Na Evolufão do Direito, que mais propriamente se denominaria O Fim no Direito (Zweck im Recht), o ponto de partida é a lei da finalidade.

No universo nada existe sem uma razão sufficiente para existir, nenhum phenomeno se produz sem uma razão sufficiente para se produzir Elimine-se pela abstracção o principio da razão sufficiente, e a existencia dos seres e a realisação dos factos se tornarão inintelligiveis para o homem. Esse principio. de que tanto cabedal fazia Leibniz, manifesta-se no mundo physico sob a forma de lei da causalidade, e no mundo psychico sob a de lei da finalidade. Toda transformação da natureza inanimada é a resultante necessaria de uma modificação anterior; dá-se um phenomeno, PORQUE se deo um outro: a pedra cahe, porque lhe foi tirado o sustentaculo; a planta morre, porque o calor attingio um gráo insupportavel para a vida vegetal. No dominio da vontade tambem não concebemos uma modificação, isto é, uma resolução ou volição, sem a sua razão sufficiente. Mas, aqui o principio da razão sufficiente reveste a forma de lei da finalidade: o homem não se determina, não age, porque, mas-afim de, para conseguir um desejado effeito. Todos os nossos actos voluntarios são dirigidos para determinados escopos. Em poucas palavras: todo phenomeno physico tem uma causa; toda resolução, ou toda acção humana, tem um fim.

No mundo material, o ser em que se realisa a modificação permanece em estado passivo. No mundo 
moral, o ser que é impellido por um fim, entra em actividade. $O$ metal que se oxyda, conserva-se inerte. $\mathrm{O}$ espirito que se resolve, actúa.

A causa está no passado; o fim está no futuro: um phenomeno physico tem por causa um phenomeno anterior; uma volição tem por causa um phenomeno ulterior, o resultado collimado.

Já nos proprios animaes a psychologia comparada nos mostra a vontade movida pelo fim. O cão bebe para o fim de estancar a sêde. Não se confunde esse facto com o da esponja que se embebe, mas não determinada por um movel, nem dirigida para um fim, que contribúa como motivo para a producção do phenomeno.

O fim - eis a alavanca que move a vontade do homem. Concebemos um estado futuro possivel, mais agradavel que o estado presente. Essa concepção nos leva a agir; é um projecto de acção offerecido á vontade pela intelligencia e pelo desejo. A aç̧ão que praticamos constitue o meio para alcançar o fim, que é o estado futuro mais agradavel que o presente.

A vontade do homem resolve-se, age, sob a pressão do interesse. Idéas abstractas, principios e conceitos da razão, deducções logicas, não têm o poder de impulsionar a vontade. Pretender, por exemplo, que o imperativo categorico de Kant seja sufficiente para pôr em movimento a vontade, equivale a suppôr que se possa fazer andar um carro de mercadorias por meio de uma prelecção sobre a theoria do movimento.

A vontade clirigida exclusivamente para o eu denomina-se egoismo. Será compativel com o egoismo a vida social? E', porquanto a sociedade, a propria humanidade, se utilisa dos serviços prestados pelo egoismo e paga-lhe os salarios por elle pedidos, interessa o egoismo na realisação dos seus fins, e por esse mocio adquire o concurso desse motor da nossa vontade. A cada momento praticamos actos que, sendo-nos uteis, 
aproveitam egualmente aos nossos semelhantes. Em um contracto de compra e venda, por exemplo, o interesse de ambas as partes se satisfaz, pois a uma convém a moéda, preço do contracto, e á outra a cousa, objecto do contracto.

Teremos, além do interesse, mais um ou alguns motivos propulsores da vontale do homem? Aqui se nos depara uma das variações, para não dizermos palpaveis contradicçōes, em que fluctúa o pensamento de Ihering, e que seus criticos com indiscutiveis fundamentos apontam na obra philosophica do illustre mestre. A principio, affirma Ihering que, ao lado do egoismo, ha um outro motor da vontade, denominado-a abnegação, o desinteresse, o espirito de sacrificio, o amor, o devotamento, a compaixão, a benevolencia, expressões todas synonymas. $O$ individuo tem o sentimento da destinafão moral de sua existencia, reconhece que é solidario com toda a humanidade. Afinal, confessa que o egoismo é o factor fundamental do nosso dynamismo psychico, o motivo ao qual todos os outros se reduzem. $\mathrm{Na}$ pratica dos actos que parecem de mais pura abnegação, de mais elevado heroismo, a analyse descobre o interesse individual.

A propria natureza serve-se do egoismo, do interesse pessoal, para fazer o homem obedecer ás suas leis: a conservação e a propagação da especie dependem de actos, para cuja realisação o prazer é um estimulo, e para cuja abstenção a dôr é um movel.

A engrenagem dos interesses individuaes, o entrozamento dos egoismos, é a base da cooperação social. O Estado, a sociedade, as relações, os negocios, toda a vida humana repousa nesta formula: ligar cada um seu proprio fim, ou interesse, ao interesse, ou fins dos outros

Interesse, motivo pratico, fim, são termos synonymos na linguagem de Ihering.

Todos os fins da existencia humana, o que quer di- 
zer -todos os interesses que pódem impellir a nossa vontade, se dividem em duas grandes classes: os do individuo e os da communhão, os fins egoisticos e os fins sociaes.

Os fins egoisticos podem ser de uma das tres ordens: physica, economica, juridica. $O$ homem existe para si mesmo; o primeiro fim proposto á vontade humana é a conservação de sua existencia. A isso chama Ihering a affirmasão physica de si. Ao contrario do que se dá com os animaes, que só se occupam com o presente e não tém a intuição do futuro, o homem pensa no dia seguinte, preoccupa-se com as condições de vida no porvir. A inquietação pelo futuro é a origem pratica do patrimonio, que constitue o meio de assegurar o bem estar material e as satisfacções intellectuaes, moraes e estheticas, pela continuação da existencia. Na formaçào do patrimonio temos a affirmafãa economica de si. A efficacia do patrimonio jaz na obrigação, a todos imposta, de respeital-o, de não impedir que o individuo accumule os bens materiaes além do necessario para satisfazer suas necessidades actuaes; e o reconhecimento dessa obrigacão é a affirmaşão juridica de si. O primeiro fim pratico que move a nossa rontade é a conservação da vida, a qual dá origem ao patrimonio, porquanto sem patrimonio não temos o futuro assegurado. A conservação da vida e o patrimonio conduzem ambos ao direito, porquanto sem direito năo temos a vida nem o patrimonio garantidos. O direito protege os dois interesses - a vida e o patrimonio, dando a cada individuo a faculdade, ou poder, legal, que se chama direito subjectivo. O reconhecimento de um direito subjectivo quer dizer que existe alguma cousa para nós, que o Estado garante a posse, o uso, ou o gozo dessa cousa. As cousas que existem para nós são divisiveis em quatro especies: i ${ }^{\text {a }}$ nós mesmos: o homem tem direito sobre os seus attributos e faculdades, sobre o 
conjuncto de seus elementos physicos e psychicos; tem o direito de personalidade; $2{ }^{\mathrm{a}}$ as cousas materiaes, de que nos apropriamos; $3 \cdot^{a}$ os nossos semelhantes, quer nas relações de familia, quer nas prestações isoladas, oriundas do clireito das obrigações; $4 .^{\mathrm{a}}$ o Estado; o homem tem o direito de cidade; a qualidade de cidadão lhe confere certas faculdades, cujo objecto é o Estado.

Ao direito corresponde o dever juridico. Ter um direito é ter um poder sobre alguma cousa das quatro especies mencionadas, equivale a saber que alguma cousa existe para nós. Estar adstricto a um dever juridico é exactamente o contrario; pois, o sujeito da obrigação existe para outrem, muito embóra esteja subordinado ao titular do direito parcialmente, e não integralmente, o que seria a escravidão.

O direito objectivo tem seu assento em tres aphorismos fundamentaes, sendo os dois primeiros concernentes aos direitos, e o ultimo ás obrigações: $I^{\circ}:-$ eu existo para mim; $2 .^{\circ}-\mathrm{o}$ mundo existe para mim; $3 .^{\circ}$ - eu existo para os meus semelhantes.

A esses tres principios Ihering chama as pedras angulares de toda a ordem juridica e moral, porquanto todas as normas que regulam as relaçōes dos individuos e dos povos decorrem dessas tres affirmações fundamentaes.

Se cada homem existe para seus semelhantes, a sociedade é um facto natural. $\mathrm{Na}$ sociedade toclas as partes componentes do todo se movem eın uma acção commuın, para o mesmo escopo. Entretanto, a força que imprime o movimento ás diversas rodas da engrenagem social é a vontade do homem, o que quer diser--as vontades diversas de milhares de inclividuos, a lucta de interesses oppostos, o antagonismo das aspirações, o embate das tendencias mais desencontradas. Como se explica a disciplina, a harmonia, a uniclade da vida social? Ha um conjuncto de moveis 
e energias que realisam esse accordo, e que Ihering denomina a mechanica social. Póde dar-se accidentalmente uma perturbação no funccionamento dos motores de coordenação social; mas, tal é a resistencia da força vital da sociedade, que a desordem se repara logo, a anarchia cede sempre á pressão das forças unificadoras, por meio das quaes a merhanica sociac coage a vontade dos homens.

Os motores da mechanica social são quatro: dois baseados no egoismo-o salario e a coaçãa ; e dois superiores, de ordem moral,-o sentimento do dever $e$ o amôr $\mathrm{Na}$ theoria do direito, Ihering só se occupa dos dois motores egoisticos. $E^{\prime}$ depois, na segunda parte da sua doutrina, quando-invertendo a ordem logica adoptada geralmente pelos fundadores de systemas philosophico-juridicos-tracta da theoria da moral, que Ihering appella para os dois factores ethicos, o amôr e o sentimento do dever, dos quaes podemos prescindir, visto como o conteúdo, ou, melhor, a base do direito, é o interesse, o egoismo, o fim pratico. Estudemos, pois, sómente estas duas alavancas da mechanica social-o salario e a coação-

Sem salario não ha relações possiveis, não se concebe a vida em sociedade. O salario constitúe o meio pelo qual se assegura a satisfacção de todas as necessidades do homem. A natureza fez o homem de tal modo, que o sujeitou perpetuamante ás duas leis fundamentaes, já conhecidas: cada homem existe para a sociedade, ou, mais propriamente, para a humanidade; a sociedade, ou a humanidade, existe para cada homem. Para satisfazermos as nossas necessidades, precisamos dos nossos semelhantes. Quanto maior o numero das necessidades sentidas pelo individuo, $e$ inces‘antemente augmentadas pela civilisação, maior a dependencia em que se acha elle em face de seus semelhantes. Sendo assim, o homem seria a mais miseravel das creaturas, se a satisfacção de suas neces- 
sidades estivesse confiada ao acaso, se não pudesse contar, com segurança, com o auxilio e o concurso dos outros homens. Esse concurso é garantido pelo salario, pela recompensa pecuniaria, movel bastante poderoso para manter na sociedade as reciprocas prestações de serviços e de cousas, o commercio juridico, como diz Ihering. A benevolencia, a sympathia, não basta, não yarante a satisfacção de todas as nossas necessidades. A prova disso é que em épochas remotas se conseguia gratuitamente o que hoje só obtemos pelo dinheiro. O progresso tem consistido exactamente em passar dos serviços gratuitamente prestados para os remunerados pelo salario. O homem que pede e recebe serviços gratuitos, que appella para a benevolencia de seus semelhantes, perde a independencia, humilha-se, e reduz-se ao papel de um miseravel mendigo. $O$ que paga aquillo que recebe, conserva a sua dignidade, e obtem muito mais facil e commodamente as cousas e serviços de que precisa. O egoismo tem o maior interesse em se pôr á disposição de cada um, em todos os tempos, e na mais larga escála possivel. No dinheiro estão a nossa independencia economica e a nossa independencia moral. E' necessario á manutenção da vida social que tudo aquillo que cada individuo presta, tenha como contra-prestação o salario, ou um equivalente.

Deve o Estado intervir pela coacção para o fim de fazer prevalecer em todas as relações sociaes o regimen do salario, ou do equivalente das prestações contractuaes? Pertencem ao dominio da justiça, ou da lei, os contractos pelos quaes os homens obtêm os meios de satisfazer suas necessidades? A justiça tem por missão assegurar a existencia de todos, é o que convém a todos. O interesse da sociedade está em que domine o principio do equivalente nas relações da vida social. Entretanto, dahi não se segue que seja sempre justificavel a intervenção da lei para obrigar os homens 
á realisação dos contractos, visto como o egoismo, o interesse individual, tem bastante força para mover, como uma das alavancas da mechanica social que é, a vontade dos individuos no sentido de se realisarem as permutas, directas e indirectas (ou por meio do numerario), sem as quaes não podemos satisfazer as nossas necessidades. Não é preciso que uma lei fixe o preço do trabalho do artifice, do fabricante, ou do negociante, por exemplo. A medida fornecida pelo egoismo é o melhor criterio da conveniencia nos contractos. A concurrencia, a liberdade contractual, corrige, em geral, as pretenções exaggeradas do interesse individual. Sómente em circumstancias especiaes deve admittir-se a intervenção da lei. Pertencem ao numero das leis destinadas a evitar os abusos e extorsões do egoismo as que comıninam penas contra a usura. Admittindo eșsa intervenção excepcional do legislador nas relações contractuaes, Ihering tem o cuidado de observar que de nenhum modo está em contradicção $\mathrm{com}$ a sua opiniño fundamental, consistente em affirmar que a vida social se basêa na satisfacção egoistica das necessidades humanas, que o interesse individual basta-comı motor da vontade-nas relações contractuaes. Nem absolutamente conviria, accrescenta, a substituição do egoismo pela coacção do Estado, porquanto o trabalho desempenhado com o fito da recompensa pecuniaria produz muito mais e muito melhor que o trabalho obrigado, ou imposto pela coacção.

O dinheiro nào é a unica forma do salario. Ha um salario ideal, recompensa dada pela sociedade como incentivo para a pratica dos actos uteis á communhão. Devemos lastimar que actualmente a sancção juridica esteja quasi exclusivamente reduzida ás penas. Em Roma não era assim: havia normas fixas sobre a concessão das honras do triumpho ou da ovação aos generaes victoriosos, ou das ordens militares-a corona muralis, civica, castrensis, navalis, aos soldados 
que na guerra se haviam distinguido por feitos de valor.

Cumpre notar que, ao lado do contracto de permuta, temos uma outra forma fundamental do commercio juridico: a associação. A associação tambem assenta no egoismo, tem como força creadora $o$ interesse pessoal, e constitúe um segundo meio de satisfacção das necessidades humanas. A differença que ha entre o contracto de permuta e a associação re side no facto de serem divergentes os fins dos contractantes no contracto de permuta. e identico, ou egual, o fim dos socios na sociedade. Certos fins praticos não pódem ser alcançados pelos esforços individuaes; exigem imperiosamente o concurso de um determinado numero de pessôas.

Tanto no contracto de permuta, directa ou indirecta (pelo instrumento da moeda), como na associação, a collectividade se serve do movel do egoismo para satisfazer as necessidades sociaes. $O$ apparelho utilisado pela sociedade forma-se, e desenvolve-se, sob a influencia desta força motriz: a finalidade, ou o fim pratico.

O commercio juridico, que, como acbamos de vêr, se realisa pelos contractos em que ha prestações de serviços ou de cousas, e pelas associaçōes. aincla encerra a efficacia de produzir a independencia do individuo, a egualdade das pessôas e a idéa de justiça. $\mathrm{O}$ homem independente não é o que tem o menor numero possivel de necessidades que satisfazer. mas o que possúe us meios de satisfazer suas necessidades. Esses meios nos são assegurados pelo commercio juridico. A continua expansão das transacções mercantis vae progressivamente augmentando a independencia do individuo. Graças á actividade e á liberdade, interna e externa, ou internacional, do commercio do nosso tempo, o pobre hoje tem maior numero de homens a seu serviço, e em todos os cantos da terra, 
do que poderia ter Creso, ainda quando esvaziasse os seus cofres. O commercio juridico é tambem um factor de egualdade: pois, só conhece um poder, o dinheiro. Não distingue entre o grão senhor e o proletario, o homem celebre e o obscuro, o nacional e o extrangeiro. Por isso, Ihering chama ao dinheiro o verdadeiro apostolo da egualdade. A idéa de justiça ainda nos é dada pelo commercio juriclico: a justiça representa o equilibrio imposto pelo interesse da sociedade entre um facto e suas consequencias para o agente, isto é, entre o facto culposo e a pena, entre o facto louvavel e a recompensa. Cada contractante recebe o equivalente do que dá, e consequentemente o commercio juridico realisa a idéa de justiça do modo mais perfeito. $\mathrm{Na}$ fixação da pena ha sempre um certo arbitrio. A fixação do equivalente, pelo contrario, é o resultado de uma apreciação cuidadosamente feita pelos interessados.

A coacção, conforme já vimos, é o segundo motor da ordem social.

Em um sentido geral, a coacção consiste na realisação de um fim por meio da sujeição de uma vontade extranha, e suppōe consequentemente uma vontade activa-a do que coage, e uma vontade passiva - a do que é coagido. Não se deve confundir a coacção psychologica com a mechanica. Esta ultima se verifica, quando a resistencia opposta pela vontade é dominada por uma pressão material mais poderosa, caso em que o agente é a pessoa que coage, e não a coagida. Na coacção psychologica, pelo contrario, o agente é o que soffre a pressão, sem deixar de agir voluntariamente. A coacção psychologica é um motivo que impelle a vontade, e não um facto externo que elimine a vontade.

Sem coacção não ha sociedade. Nas edades mais remotas, como em os povos mais atrasados actualmente, o mais torte da collectividade é quem, impel- 
lido pelo seu interesse, coage os consociados á pratica dos actos que lhe apra\% ordenar. Nesse periodo da vida social, o egoismo dos fortes esmaga os fracos. Mas, pouco a pouco se vae esclarecendo e orientando o proprio egoismo. Em vez de matar o vencido, o vencedor, guiado pelo se!s interesse bem comprehendido, faz delle um escravo. O escravo se resgata, ainda no interesse do senhor, ou paga um tributo ao chefe, e incorpora-se á classe dos homens livres. Essas transições são determinadas pela evolução, pelo progresso, do egoismo. Sempre o fim pratico a dirigir o homem; sempre a lei da finalidade a dominar a vontade.

Esse dominio primitivo da força era necessario. Se a força não tivesse esmagado as resistencias da vontade individual, se não tivesse habituado o homem á disciplina e á obediencia, como se teria podido fundar o imperio do direito? Os tyrannos, os mais perversos despotas, têm feito tanto em favor do direito, como os mais sabios e brandos legisladores. Era indispensavel o concurso de uns e de outros, para se formar o direito de que hoje gozamos. Se não tivessem sido precedidos dos dominadores voluntariosos, os organisadores da norma juridica nada teriam conseguido. Os povos antigos tiveram uma intuição dessa verdade: para elles a força não tinha o caracter monstruoso que tem para nós. Sujeitavam-se á violencia dos seus chefes, ás maiores atrocidades dos governantes, sem que manifestassem a mais ligeira revolta do sentimento do direito e da fraternidade humana. E' que nas crueldades mais hediondas viam apenas a acção das forças naturaes. Não têm razão, continúa Ihering, os que censuram á Providencia o ter abandonado o homem nesses primeiros passos da vida: o que então se deo, era necessario; sem esse dominio da força bruta teria sido impossivel a formação do direito.

No dominio do direito a força hoje desempenha outro papel. De creadora do direito se transformou 
em serva do direito organisado. O egoismo, ou o interesse, regulamentado, subordinado a normas, é protegido pela força. Na legitima defesa se nos depara a primeira applicação da força de que necessita o fim da existencia humana. Ameaçado em sua vida, ou em seu corpo, o homem repelle a força pela força. A defeza do individuo não se restringe á sua personalidade; abrange tambem o seu patrimonio. Defender-se, no sentido amplo da expressão, quer dizer-defenderse a si e os seus bens. No seio da familia e nos contractos, o sujeito do direito trava relaçðes com outra pessôa, relações que são permanentes no primeiro caso, e passageiras no segundo. Apparece, então, a necessidade de meios de defeza mais amplos. A natureza incumbio-se de desenhar os lineamentos fundamentaes da primeira instituição: em face da mulher, a força physica do marido e o trabalho mais pesado que está a seu cargo, lhe asseguram a preponderancia. Deante dos filhos, a propria fraqueza e dependencia em que estes se acham nos primeiros annos, mantêm ao pae a auctoridade e a força de que precisa, para dirigil-os. A natureza, diz Ihering, não quiz que o homem entrasse na sociedade civil, sem primeiro habituar-se á subordinação na vida de familia.

No que toca aos contractos, que se formam, já mostrámos, em virtude da alavanca da recompensa, ou salario, a coacção não se faz necessaria á protecção de todos. Assim que a compra e venda e a troca, operações que se realisam em um só momento, dispensam a protecção da força. Poder-se-hia objectar que o comprador deve ser defendido-como possuidor da cousa comprada, e o vendedor-como possuidor do preço; mas, para isso basta a proteç̧ão do patrimonio, de que já nos occupámos. A proteç̧ão especial dos contractos apparece, quando se tracta das convençбes que implicam necessariamente o adiamento da prestação, a idéa de praso, isto é, uma promessa. A 
funcção pratica da promessa não se realisaria, se lhe faltasse a força obrigatoria. A vontade do devedor se vincula, porque sem esse vinculo não seria attingido o fim pratico, o interesse reciproco, que os contractantes têm em mente, quando celebram o contracto.

A coacção, ou a força de que dispõe o direito é, pois, necessaria para defender a existencia do homem, o patrimonio, a familia e os contractos. Mas, de que serviria a coacção ao titular de um direito, isto é, ao que defende um desses interesses, se o seu adversario tambem pudesse empregar a força? Para organisar a coacção na sociedade, cumpre pôr a preponderancia da força do lado do diveito. E' facil, nota Ihering, ladear a difficuldade desta questão, dizendo que o Estado já realisou a tarefa, e que nada mais ha que fazer nesse sentido. Porque já conseguiu o Estado alliar a força ao direito? A explicação está em que o interesse geral prevalece sobre os interesses particulares do individuo. Quando os interesses da communhão estão ameaçados, todos os cidadãos entram em combate; quando se tracta de um interesse particular, só $o$ individuo se agita.

Desde que a sociedade tem, disciplinada, regulamentada, a força necessaria para exercitar a coacção, surge o Estado. O Estado, pois, é a propria sociedade a usar do seu poder de coacção; é a organisafãa da coação social. Quem diz-Estado diz-força social disciplinada. O conjuncto das normas que formam essa disciplina é o direito. Qual o conteúdo, ou a materia, dessas normas, é o que depois veremos. Por emıquanto, basta sabermos que a organisação da coacção social presuppõe-o estabelecimento do mechanismo exterior da força, isto é, o poder publico, e o conjuncto das normas que lhe regulam o funcionamento, isto é, o direito.

Temos verificado até aqui dois elementos no direito: a norma e a coação, meio de garantir a obser- 
vancia da norma. O direito está todo encerrado nos estatutos sociaes sanccionados pela coacção publica. Só as prescripções garantidas pela força do Estado constituem normas juridicas. O Estado é a unica fonte do direito.

Poder-se-ha objectar, como já se tem feito, que a coacçáo organisada não é elemento essencial do direito, porquanto o direito internacional, e aquella parte do direito publico interno que nas monarchias determina os poderes e obrigações dos monarchas, não têm sancção organisada, o que não impede a linguagem universal de com razão denominar normas juridicas as duas especies de regras alludidas. $\mathrm{Na}$ verdade, ha uma coacção que assegura dentro de certos limites a observancia das duas ordens de preceitos: para os do direito das gentes temos a guerra, e para os do direito publico interno-a revolução. A revolução e a guerra desempenham no direito internacional e no direito publico o mesmo papel que a lucta physica já teve na formação do direito privado. $O$ direito das gentes ainda está na phase por que, ha muitos seculos, passou o direito privado.

A norma é o lado interno do direito; a coacção o lado externo. Norma quer dizer-regra segundo a qual o homem deve dirigir sua conducta. Não se confunde a norma com a maxima. A maxima indica o modo como devemos proceder, em se tractando de actos que praticamos livremente. A norma, pelo contrario, impóe á vontade de outrem a direcção que cumpre seguir. Toda norma é um imperativo, e o imperativo só se comprehende, quando alguem tem o poder de impôr sua vontade a outrem. O imperativo suppõe sempre duas vontades.

A ordem moral do mundo é mantida por tres especies de imperativos: os do direito, os da moral e os dos bons costumes. Todas essas normas sáo estabeltcidas no interesse social. As regras do direito são rea- 
lisadas pelo Estado; as da moral e dos bons costumes pela sociedade.

O fim pratico da justiça é a egualdade. A justiça MATERIAL estabelece a egualdade INTERNA, que quer dizer - a justa proporção entre os merecimentos e a recompensa, entre a culpa e a pena. A justiça Formal assegura a egualdade ExTERNA, que quer dizer-a applicaçáo uniforme, a todos os casos, da norma promulgada. Ao legislador compete realisar a justiça interna. Ao juiz--applicar a justiça externa.

Mas, o fim da justiça será realmente a egualdade?

Terá o direito por missão estabelecer a egualdade entre os homens? Que vale a egualdade, quando é certo que podemos ser todos eguaes na miseria? Não parece até que o fundamento da egualdade está na malevolencia e na inveja, os mais vergonhosos refolhos do coração humano? Queremos a egualdade entre os homens, porque é ella a condição do bem da sociedade. Sem a egualdade não ha paz social. Não são unicamente os individuos collocados em posições sociaes inferiores os que soffrem com as desegualdades sanccionadas pelo direito. A lucta dos que soffrem contra as classes privilegiadas abala todo o organismo social, e é prenhe de consequencias funestas para todos os membros componentes do todo. Não ha um imperativo categorico a priori que imponha a egualdade a todas as relações humans. E' o interesse pratico da existencia e da prosperidade da sociedade que a subordina a principio da egualdade. Se a experiencia algum dia demonstrar que a sociedade tem interesse em adoptar um systema de desegualdade juridica, a desegualdade será necessariamente estabelecida. Deve-se attender á utilidade social, e nåo ao que convém ao individuo. Se tivessemos em conta o interesse do individuo, chegariamos á consequencia absurda de uma egualdade exterior, mechanica, na qual se nivelariam grandes e pequenos, ricos e pobres, adultos e infantes, homens sensatos e loucos. Applicando-se 
un tractamento egual a seres deseguaes, o resultado seria a mais flagrante das desegualdades. Nenhuma sociedade resistiria a tal regimen. Assim, a egualdade que o direito reconhece e garante, é relativa, e consiste na proporção entre a culpa e a pena, entre a capacidade, ou os meritos, e o salario, ou a recompensa. Eis a base da verdadeira justiça. Injusta é, por exemplo, a lei que impõe os mesmos encargos economicos ao pobre e ao rico, ou a que pune com a mesma pena a contravenção e o crime.

E' sempre o egoismo que disciplina o homem, e o impelle a formar normas juridicas. A experiencia mostra a cada individuo que a offensa por elle feita ao direito de outrem expõe os seus proprios direitos a ameaças e violações, e que, respeitando os direitos alheios, contribue cada qual para a formação de um meio social em que seus direitos sejam egualmente respeitados.

Até aqui temos estudado dois elementos do direito, a norma e a coacção, dois elementos puramente formaes, que nada nos dizem sobre o conteúdo do direito. Sabemos apenas que a sociedade exige de seus membros certas acções e abstenções. Mas, qual a causa, e qual o fim, dessas injuncções? Qual a missão do direito? Dir-se-ha que o problema é insoluvel, porquanto o conteúdo do direito varia eternamente. O que hoje se veda - amanhã se permitte, o que aqui é ordenadoalém é prohibido. Fé e superstição, selvageria e civilisação, vingança e amôr, crueldade e humanidade, tudo tem sido acolhido e consagrado pelo direito. Se a missão do direito fosse realisar o verdadeiro, o resultado até hoje obtido seria desolador. Se essa fosse a missão do direito, forçoso seria confessar que o direito tem sido o joguete do erro perpetuo. Cada seculo que transforma o direito, lavraria a condemnação do seculo antecedente, e por seu turno seria condemnado pelo seculo seguinte. A verdade estaria sempre alguns passos além do direito, que nunca a alcançaria, á guiza da criança a 
perseguir a borboleta que vôa ao lhe sentir a approximação. A sciencia é uma eterna investigadora; mas, esta descobre, e as verdades que ella descobre, lhe constituem uma acquisição perpetua, um patrimonio para sempre. No seu dominio, nenhum poder tem o dom de revestir o erro da auctoridade da verdade. A razáo dessa differença está em que a verdade é o fim do conhecimento, e nao dos actos. A verdade é uma só, e tudo que della se afasta é erro. Para os actos, para a vontade, ao contrario, não ha medida absoluta. Em situações diversas a vontade actúa differentemente, e, sem embargo, póde ser sempre justa e opportuna. A vontade é julgada-segundo o fim que se propõe. A justeza, a adaptação dus meios aos fins, constitúe a medida do pratico, assim como a verdade é a medida do theoraco. Do medico que prescreve um remedio contrario ao indicado pela molestia, ninguem diz que receitou um remedio falso, mas, sim, que não applicou o meio adequado para conseguir o fim. O medico não prescreve o mesmo remedio para todas as molestias. Do mesmo modo, o direito não estabelece sempre e por toda a parte as mesmas disposições; mas, adapta os seus preceitos ao estado do povo, ao gráo de civilisaçáo, ás necessidades da épocha. Suppôr que o direito deve ser o mesmo em todos os pontos do globo, é tão absurdo como acreditar que podemos submetter todos os doentes ao mesmo tractamento. Ha, sem duvida, regras de direito admittidas por todas as nações; todos os povos punem o assassino e o bandoleiro, todos consagram o Estado, a propriedade, a familia e o contracto. Eis ahi, poderão dizer, verdades juridicas absolutas. Não: com esse criterio poderiam qualificar de verdades as casas, as ruas, a vestimenta, o uso do fogo e o da luz, instituições fundamentaes da civilisação humana, que são apenas resultados da experiencia applicada á realisação de certos fius humanos. Garantir a segurança das vias publicas contra os crimes dos salteadores, 
constitúe um fim, do mesmo modo que defender os logares em que a vida dos homens corre perigo, por meio de diques, contra as inundações. O direito é uma sciencia que tem por objecto a opportunidade (!). As leis uniforme e permanentemente consagradas formam o opportuno que resistio á prova dos seculos, a opportunidade consolidada pela experiencia. $\mathrm{O}$ direito inteiro é creação exclusiva do fim. Indagar o fim das instituições - eis o mais elevado objecto da sciencia juridica.

Qual é o fim do direito? O fim dos actos de todo animal é a realisação de suas condições de existencia. A vida animal consiste na adaptafão pratica do mundo exterior aos fins da existencia propria. Assim sendo, podemos dizer que o direito representa a forma $d a$ garantia das condifóes de vida da sociedade, assegurada pelo poder de coaçãão do Estizdo.

Para bem comprehendermos a definição, precisamos saber em que consistem as condiföes de vida. Esta noção é relativa. Se encaramos a vida sob o aspecto material, suas condiçбes se reduzem ás necessidades physicas: o comer, o beber, a vestimenta, a habitação. Aqui mesmo, a noção é relativa, porquanto as necessidades variam, tal individuo exige mais, tal outro tem necessidade de outra cuusa. Mas, a vida não se encerra na existencia physica. São tambem condições de vida todos os bens, todos os gozos que, no sentir do individuo, dão apreço á existencia. A honra, a liberdade, a nacionalidade, não são condições materiaes da vida. $\mathrm{E}$, entretanto, para o homem que zela a sua honra, sem esta que valôr teria a vida? Para os povos que amam a liberdade, a morte seria preferivel á escravidão.

Se o direito tem por objecto as condiçðes de vida da sociedade, como se explica o facto de prohibir aqui o que além auctorisa ou ordena? Não parece que factos táo diversamente apreciados não se pódem reputar condições de vida? A essa objeç̧ão responde Ihering 
que a opportunidade é sempre relativa. $\mathrm{O}$ medico náo se contradiz, quando, acompanhando as phases differentes da molestia, prescreve hoje o que hontem prohibia. Dá-se o mesmo com a sociedade, cujas condições de vida variam. Alguns exemplos mostram como o direito se modifica no que diz respeito a uma mesma condição. O ensino elementar hoje é obrigatorio. Outr ora estava entregue á iniciativa particular. Em cert's Estados da America do Norte, sujeitos ao regimen da escravidão, era prohibido, antes da guerra civil, e reputava-se crime capital-ensinar a ler e escrever aos negros. Neste assumpto, o Estado tem assumido uma quadrupla attitude: coaç̧ão para garantir a realisação do fim; realisação do mesmo fim pelos meios ministrados pelo Estado, mas sem coacção; indifferença corn. pleta do Estado; prohibição, sob pena de morte, da realisação do fim para certas classes da sociedade. Todas essas posições do Estado em face do ensino primario são justificaveis. Onde ha escravos, é legitimo o procedimento do Estado que prohibe a instrucçáo dos mesmos: um escravo que sabe ler e escrever é uma ameaça á sociedade. $\mathrm{Na}$ antiguidade havia completa indifferença do Estado em relação ao ensino elementar, porque este não era tido como condição de vida social. A animação do Estado, sem coacçáo, exprime a crença de que a educação escholar é desejavel, conveniente, mas não necessaria. $O$ ensino obrigatorio estabelece-se, depois que se generalisa a conviç̧áo de que é necessario. Cada uma dessas concepçóes tem o seu momento opportuno. Todas são justas, perfeitamente legitimas. Quando surgio o christianismo, o Estado pagão o perseguio a ferro e fogo, porque na religião nascente via um perigo para a sua existencia. Mais tarde, esse mesmo Estado, que sob pena de morte vedava a profissão da fé christã, impoz esta religião pelos meios mais atrozes. E' que a principio o Estado suppunha não poder coexistir com a nova religião; 
convenceo se depois de que não podia subsistir sem ella. Qual desses modos de vêr era o verdadeiro? Ambos, cada um na sua épocha.

Póde se ainda observar que tanto o direito não ga rante as condições de vida da sociedade, que muitas vezes estatúe preceitos em manifesta opposiçáo aos interesses da sociedade. $\mathrm{Na}$ edade media, por exemplo, a sociedade, inspirada pela Egreja, punia com as mais severas penas as feiticeiras e os magicos. A isso responde Ihering, distinguindo entre condiçoes objectivas, reaes, da vida social, e condições subjectivas, isto é, erroneamente consideradas taes. A sociedade e a Egreja na edade media estavam convencidas de que os magicos e as feiticeiras constituiam uma séria ameaça para as proprias bases da sua existencia; e, consequentemente, o motivo que subjectivamente armava o seu braço era a garantia das condições da vida social. A minha noção de condifóes de vida, accrescenta Ihering, contém as condições subjectivamente tidas como taes.

As condições de vida da sociedade se dividem em tres classes: extra-juridicas, mixtas e juridicas. $\mathrm{O}$ direito nada tem que vêr com as primeiras, que dependem da natureza. E' uma condição de vida extra-juridica que o frio e o calor não ultrapassem certos limites. Que póde fazer o homem para se garantir essa condição de existencia? Condições mixtas são aquellas em parte asseguradas por certos moveis que dominam o homem, e em parte pelo Estado. Taes se nos revelam a conservafãa e a propagafão da vida, o trabalho $\mathrm{e}$ as relaf̧ões sociaes. $\mathrm{O}$ instincto de conservação, o instincto sexual e o amôr ao ganho, em geral, bastam para nos garantir aquellas condições de vida. Quando falham esses motores, a intervenção do Estado se faz necessaria. Assim, por exemplo, o instincto sexual é sufficiente, em regra, para levar o homem á propagação da especie; mas, algumas vezes o homem se rebella contra a natureza, reduz os nascimentos, destróe os 
germens da vida, mata os recem-nascidos. Então, o Estado estabelece as suas penas para conjurar o mal, porquanto qualquer ameaça á reproducção da especie constitue um perigo evidente para a sociedade. Além das condições mixtas, cuja realisação depende mais dos tres moveis assignalados que da acção do Estado, temos as condições puramente juridicas. São todas aquellas que a sociedade só póde assegurar-se pela coacção juridica. O pagamento das dividas, a obediencia ao Estado, a contribuição para as despezas publicas, são injuncções impostas á nossa vontade pela coacção do Estado unicamente, sem que nenhum movel natural arraste a vontade do homem a cumprir esses preceitos.

Todas as regras de direito têm o homem por fim, isto é, são creadas no interesse do individuo. Quando se diz, pois, que o direito garante pela coacção as condiçōes de vida da sociedade, não se quer affirmar que haja condiçōes de vida social em opposição ás condiçoes de vida do individuo. Desde que se saiba que a sociedade é uma condição de vida para o individuo, comprehende-se que as condiçōes de vida da sociedade nada mais são do que condiçōes de vida mediatas, ou indirectas, para o individuo.

Tão estreito é o vinculo que prende o individuo ao Estado, tal é a solidariedade que ha entre os dois seres, que cada homem bem poderia repetir com verdade a phrase de Luiz XIV: "o Estado sou eu?. O individuo, no maior numero dos casos, ignora essa identificação dos seus interesses com os do Estado. E com razão poderia perguntar ' se o Estado sou eu mesmo, para que me coagem a dar o que o Estado me pede? Eu cuido espontaneamente dos meus interesses, sem necessidade de meios coercitorios '. A coacção, replica Ihering, é organisada no interesse do proprio coagido. Quando o mestre obriga o discipulo a estudar, o discipulo soffre um constrangimento imposto pelo seu interesse: como em virtude da pouca edade não com- 
prehende a utilidade propria, crêa-se uma coacção artificial, para obrigal-o á pratica de actos cuja vantagem só na edade da razão comprehenderá. Do mesmo modo, o Estado nos compelle a fazer aquillo que, se tivessemos a comprehensão do que nos é necessario, realisariamos espontaneamente.

A coacção organisada pelo Estado tem uma dupla razão de ser. A primeira é a ausencia de uma noção exacta dos verdadeiros interesses, da parte do individuo. Nem todos chegam a comprehender que o interesse geral e o interesse particular se reduzem a um só interesse. Quando se tracta da cullisão entre dois interesses, um presente menor, e outro futuro-maior, o homem em geral sacrifica, por falta de previdencia, o interesse maior ao menor. Isto posto, a lei póde ser definida: a colligaşão das pessôxs intelligentes $e$ previdentes contra as que são incapazes de prevêr. As primeiras obrigam as ultimas a agir de accordo com seus interesses bem comprehendidos, o que é agir de accordo com os interesses de toda a collectividade. A lei é a arma indispensavel de que se serve a intelligencia na lucta contra a estupidez. A segunda razáo jaz no facto de, frequentemente, a vontade-. por fraquesa ou perversidade-sacrificar o interesse geral, remoto, ao particular, immediato.

Tudo o que vem de ser dito, demonstra a necessidade da coação.

Eis, a largos traços, e-tanto quanto foi possivelpelas proprias palavras do auctor, a theoria philosophico-juridica de Ihering.

Da resumida exposição feita resaltam as seguintes affirmafões fundamentaes

a) a vontade do homem está subordinada á lei $d a$ finalidade: actúa, resolve-se, dirigida para um fim, que é o motivo que a impelle;

b) no direito a analyse descobre tres elementos, dois 
formaes-a norma e a coacção, e um material-o interesse, que é o fim pratico, impulsor da vontade;

c) o interesse, conteúdo do direito, varia frequentemente, visto como a sociedade constantemente se engana, suppondo hoje que é do seu interesse, ou condição de sua existencia, o que amanhã repelle e condemna por julgar contrario ás proprias bases de sua existencia ;

d) primitivamente, e esse phenom ‘no necessario é um bem, a força bruta domina as vontades, firmando a disciplina e a uniclade da sociedade; pouco a pouco, a força vae sendo dirigida pelo interesse pratico da collectividade, e torna-se um instrumento para a realisação dos fins sociaes;

e) a missão do direito é garantir pela coacção do Estado as condições da vida social, quer objectivas ou reaes, quer subjectivas ou erroneamente reputadas taes;

f) corollario das proposiçoes anterioies é a affirmagão de que o methodo proprio do direito é o teleclogico, porquanto o direito não procura descobrir verdades, como em geral as demais sciencias, mas unicamente adaptar os meios á consecuçáo dos fins, isto é, á realisação dos interesses sociaes.

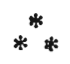

Em meio do renovamento por que estão passando as sciencias sociaes, em consequencia da applicação do methodo positivo ao seu estudo, uma fatalidade tem perseguido o direito. Os profundos pensadores, os philosophos que bem comprehendem o que é a sciencia e o que é a philosophia, não se têm dedicado com o mesmo interesse ao conhecimento do direito: a obra de Spencer, a Fustzsa, por exemplo, admiravel nos primeiros capitulos-consagrados ás bases do direito, decahe, descamba em noções vulgares, 
quando começa a applicar os principios, soberbamente lançados-como alicerces inabalaveis, á constituição da sciencia juridica. Os grandes jurisconsultos, aquel. les que conhecem profundamente a historia do direito e a dogmatica juridica, revelam incrivel ignorancia do que é a sciencia em geral, e do que é a philosophia, tal como hoje se concebe: a Evolucão do Direito de Ihering é uma prova do que affirmamos. Ainda não se fez a hypostase da sciencia com o direito, sem embargo de ser o direito a sciencia social que, pela natureza dos seus factos-manifestados por costumes e leis, e já muito observados e classificados, mais cedo devia constituir-se. Mais de vinte seculos de empirismo, em que as mais anti-scientificas concepções religiosas e dos subjectivistas, transmittidas de geração em geraçāo, e cegamente admittidas no mundo dos juristas, foram cimentando profundamente o divorcio do direito com a sciencia, de tal modo dessoráram o cerebro dos legistas, que mesmo hoje é raro encontrar um jurisconsulto que tenha a mais ligeira noção do que é sciencia, e do que é methodo scientifio. *)

A theoria philosophico-juridica de Ihering tem o defeito capital de nos dar mais uma doutrina sem base scientifica, para se juntar ás innurneras de que está repleta a litteratura juridica.

O ponto de partida de Ihering é a distincção entre a lei da causalidade e a da finalidade, para concluir que a vontade humana está sujeita á ultima, e não á primeira.

Ninguem póde com fundamento contestar a diffe-

(*) Para comprovar a asserção, transcrevemos o seguinte trecho da obra de um jurisconsulto contemporaneo, de notavel erudição: "Pesquizar das leis communs, constantes e universaes, directoras da vida juridica dos povos, é indusir leis geraes, affirmando principios a priori, para objectiva e subjebtivamente proclamar verdades sociologicas absolutas. Que se deve esperar da applicação do methodo positivo, o unico que as sciencias hoje reconhecem como verdadeiro, no dominio do direito, quando um dos mais illustres jurisconsultos que pretendem admittir esse methodo, confunde de modo tão deploravel as noções elementares de inducgãa e deduç̧ão? 
rença evidente entre o mechanismo das causas materiaes e o da vontade. A lei da causalidade ná se manifesta do mesmo modo em um e outro caso. A lei da causalidade reveste tres modalidades distinctas: nos phenomenos mechanicos, physicos e chimicos, é a causafão; no mundo vegetal é a excitafão; no mundo da vontade-a motivaf̧ão. Na causaçào e na excitação, a causa actúa sempre por um contacto material com o ser em que se produz o phenomeno. $\mathrm{Na}$ motivação, a causa actúa por intermedio da intelligencia, produzindo representações, ou idéas, que, auxiliadas pelo sentimento, impellem a vontade. Tantas vezes temos exposto esta theoria da motivaçáo em escriptos diversos (theoria que Schopenhauer ensina melhor de que qualquer outro philosopho), que nos julgamos dlspensado de desenvolver o assumpto. (*)

A vontade é movida pelo motivo, ou, digamos com Ihering, pelo fim pratico, o que é a mesma cousa. As nossas voliçōes são o producto-em parte da nossa constituição psychica e em parte dos motivos. Neste ponto, ainda Ihering parece acceitar o ensinamento da sciencia, porquanto diz (n." 7) que a concepção que impelle a vontade reside, em parte na propria pessôa que se determina, na sua individualidade, no seu caracter, nos seus principios, no seu modo de encarar a vida, e em parte nas influencias exteriores. Entretanto, quando se procura averiguar se Ihering professa o livre arbitrio, ou o determinismo, sem o qual não se comprehende o direito, não é possivel penetrar bem o pensamento do jurisconsulto. O'ra, a vontade do homem, conjunctamente com a vontade de Deus, a cuja imagem foi creado o homem, constitúe a verdadeira força creadora do mundo (n." I 3 ); a actividade do homem depende do seu livre arbitrio

(*) Vide Revista da Faculaade de Direito de S. Paulo, vol. 2. ${ }^{\circ}$, pag. 126 e seguintes, e a Introduç̧ão á Historia da Civilisação na Inglaterra, de Buckle, traduç̧ão de A. Melchert, pag. $3^{8}$ a $5^{2}$. 
(n. $\left.{ }^{\circ} 45\right)$ : a vontade do homem, differente das outras forças da natureza, é dotada de liberdade ( ${ }^{\circ}{ }^{\circ}$ 50); a naturesa nenhuma acção exerce sobre a vontade humana ( . $^{\circ} \mathrm{I} 3$ ) ; óra, a nossa vontade de tal modo está presa aos motivos, que náo podemos deixar de fazer o que fazemos; é assim que, se a historia universal se repetisse cem vezes, cem vezes a humanidade seria forçada a organisar o direito n. ${ }^{\circ}$ (I I5); só concebe a idéa de um crime quem é por sua natureza delinquente, assim como só concebe a idéa de uma acção bôa quem é por sua natureza virtuoso (n." 7).

Vê-se que o pensamento de Ihering oscilla entre o livre arbitrio e o determinismo. Não ha na Evolução do Direito uma conviç̧ão precisa e segura no que toca a esta magna qnestão philosophica, que os espiritos frivolos desdenham, mas que para os pensadores, dignos deste nome, é "o problema philosophico por excellencia», a chave que nos dá a solução de innumeras difficuldacles das sciencias sociaes.

$\mathrm{E}$, assim, a distinç̧ão entre causalidade e finalidade, feita por Ihering, ficou reduzida ao reconhecimento de uma verdade banal, que nenhum espirito esclarecido põe em duvida. Tanto os adeptos do livre-arbitrio, como os sectarios do determinismo, estão concordes em que o mechanismo da vontade differe do das causas materiaes, ou do mundo physico. O que nos interessaria, era saber se a vontade, subordinada á lei da finalidade, movida por um fim, é arrastada necessariamente por esse motivo, ou póde resistir lhe. Nesse ponto, Ihering não se pronuncia com segurança, não se revela um philosopho, repete mal e contradictoriamente o que já tem sido tão claramente explanado.

$O$ ponto de partida da theoria de Ihering é a reproducção de uma verdade philosophica seın alcance, que póde ser admittida em qualquer systema. Ficamos sabendo que a vontade humana se move pelo interesse, o que é uma verdade banal, estafadissima. 
Mas, não sabemos se a vontade póde, ou não, resistir á pressão do interesse.

Teremos ao menos um conhecimento exacto do que é o interesse, motor da vontade? Absolutamente não.

Dos tres elementos que a analyse descobre no direito, sómente os dois primeiros, puramente formaes, a norma e a coacção, foram caracterisados com segurança, determinados de modo preciso.

O'ra, esses dois elementos formaes constitúem exactamente a materia indiscutivel na generalidade dos systemas philosophico-juridicos. A norma, define Ihering, é uma regra segundo a qual o homem deve dirigir sua conducta, um imperativo que ordena ou prohibe. A coacção, accrescenta o illustre jurisconsulto, ou a força organisada do Estado ao serviço do direito, constitúe o criterio absoluto do direito. Pela coacção conhecemos immediatamente que a regra de que se tracta, é uma norma juridica. Até aqui nada temos na doutrina de Ihering, que não seja a reproducção de uma verdade evidente e acceita por todos os systemas, se exceptuarmos os dos raros escriptores que acreditam que com o desenvolvimento da cultura moral e intellectual da humanidade será possivel dispensar a sanç̧ão physica do Estado em um futuro mais ou menos remoto, hypothese que o estudo da constituição psychica do homem na actualidade não nos permitte admittir.

Percorramos todas as theorias philosophicas sobre o direito, e havemos de vêr que o ponto de divergencia está exactamente na questão de saber qual é o conteúdo, ou a materia, das normas juridicas. Para a escóla theologica, o conteúdo da norma juridica $\epsilon$ um preceito estabelecido e revelado por Deus, ou deduzido de algum principio moral creado pela vontade divina, e conhecido pelo meio sobrenatural da revelação. Para a escóla de Kant, o conteúdo da 
norma juridica é uma deducção do principio que affirma ser justa toda acção que não crêa obstaculo á harmonia da liberdade de arbitrio de cada um com a de todos. Para a de Krause, o conteúdo da norma juridica é uma das condiçōes temporaes da vida, dependentes da liberdade. Para a de Bentham, o conteúdo da norma juridica é um interesse social, interpretado ou apurado segundo o criterio que nos offerece em preceitos muito positivos. $E$ assim para a generalidade das escólas. Nenhuma discute os dois elementos formaes, a norma e a coacção, que a mais perfunctoria analyse nos revela no direito de todos os tempos.

A grande difficuldade da materia consiste em averiguar porque se estabelece a norma, garantida pela coacçáo; que necessidade ha desse conjuncto de regras; qual o criterio que nos deve dirigir na formulação das normas juridicas.

Como resolve Ihering essa difficuldade? Dizendo-nos que o conteúdo da norma juridica é o interesse da sociedade, que, em ultima analyse, se reduz ás condições da vida social, reaes, ou erroneamente consideradas taes.

O conteúdo do direito na escola de Ihering é o interesse, e o interesse variavel, o interesse de cada épocha, de cada sociedade, o que cada povo suppõe ser seu interesse. Hoje o Estado pune com a pena de morte os que professam uma religião differente da sua. Amanhã obriga sob a mesma pena a professar a religiro antes condemnada. Qual das cluas leis é a expressão da verdade? Nada temos com a verdade. O direito não tem por objecto a verdade, mas a utilidade; e sob o aspecto da utilidade ou do interesse social, ambas as leis pódem ser perfeitamente bôas. O direito não se formula em virtude de raciocinios ou deducçōes, mas em consequencia da lucta dos interesses (n. ${ }^{\circ}$ I I 8). Não ha, pois, um criterio fixo por meio do qual se 
possam distinguir as leis justas das injustas. Todas as leis são justas, legitimas, porque são promulgadas para resguardar o interesse, objectivo ou subjectivo, da sociedade.

A força ao serviço clo interesse variavel, eis, em synthese, ao que se reduz o direito segundo a concepção de Ihering. O direito não tem principios; não ha leis que dominem os phenomenos juridicos; a observação nada nos mostra de commum, constante, invariavel, nos factos juridicos. Não é possivel constituir uma sciencia do direito. Será possivel formar a arte do direito? Tambem não, porquanto, como bem ensina Stuart Mill, a arte se compõe das verdacles da sciencia, dispostas na ordem mais conveniente para a pratica, e não para a theoria (*). A arte formula os seus preceitos, baseando-os nas verdades geraes, nas leis, de uma ou mais sciencias. A medicina, por exemplo, considerada como arte, encerra determinações deduzidas das verdades geraes, ensinadas pela pathologia, therapeutica e outras sciencias.

Applicando a seu modo o methodo teleologico, Ihering crêa uma doutrina que não é sciencia, nem arte. Nem seria licito applicar hoje o processo teleologico com a pretenção de constituir uma sciencia qualquer. Adaptar os meios á consecução dos fins, e é isto o unico resultado que nos dá o methodo teleologico, póde ser-quando muito - formar uma arte, se a relação entre os meios e os fins traduz leis scientificas. Sciencia (quando no mundo dos juristas será comprehendida esta verdade?) quer dizer conjuncto systematico de conhecimentos verdadeiros e certos sobre leis, isto é. sobre o que ha de constante, geval, uniforme, na producsão dos phenomenos. Todas as sciencias se reduzem a conhecer as leis dos factos, e o unico methodo que com segurança póde ministrar-nos o que

(") Systhème de Logique Déductive et Inductive, liv. VI, cap. XII. 
ha de permanente na reproducção dos phenomenos é o methodo positivo. Basta sabermos que o methodo de Ihering é o teleologico, para immediatamente comprehendermos que a sua theoria nada tem de commum com a sciencia.

A Evolução do Direito é a negação do direito, porque é a negação de quaesquer principios e leis superiores ao direito positivo. Um direito positivo que se organisa excluxivamente para proteger interesses reaes, ou suppostos, de uma dada épocha, é um direito sem base segura, sem raizes profundas na sociedade, um direito cuja suppressão perfeitamente se comprehende.

Será essa a conclusão de Ihering? Quando elle tenta explicar-nos que o conteúdo do direito é o interesse, real ou supposto, e sempre variavel, parece que sim. Mas, quando por momentos é forgado a reconhecer que o direito tem seu fundamento na natureza humana, individual e socialmente encarada, parece que não. E' que a verdade por vezes se impõe ao espirito do eminente jurisconsulto, e então elle escreve phrases como esta: QQuem pratica um acto pela satisfacção ou prazer que esse acto lhe promette, ou se abstem de outro pelo temor de um mal, age impellido pelo seu interesse, mas ao mesmo tempo obedece á lei da natureza». Outras vezes, o raciocinio trahe o espirito de escóla, o desejo de originalidade, e nos leva a affirmar exactamente o contrario do que ensina o grande jurista. Assim que a sua celebre comparação do direito com a medicina demonstra que a medicina, e com ella o direito, são sciencias, têm por objecto a verdade, e não sómente o util. Do medico que prescreve um remedio contra - indicado para uma certa molestia, affirma Ihering, ninguem diz que receitou um remedio falso, mas, sim, que não vio com justeza, que não attingio o fim collimado. Ora, o medico que applica um medicamento, exercita uma arte, pøe em pratica um preceito artistico; mas, o preceito tem por base 
uma ou algumas verdades scientificas, o conhecimento de algumas leis a que estão subordinados certos phenomenos. $\mathrm{O}$ medico que receita mal, commette um erro de pathologia, por suppôr que se trata de uma molestia, quando outro é o mal de enfermo, ou por acreditar curavel o que a sciencia tem verificado que não se cura, ou um erro de therapeutica, por attribuir a um medicamento propriedades que lhe fallecem. Antes de se propôr um fim pratico, é necessario que o medico conheça certas verdades geraes, certas leis. A arte precisa ser precedida ou illuminada pela sciencia. Do mesmo modo, quando o legislador crêa uma instituição, ou promulga um conjuncto de normas juridicas, precisa bem averiguar previamente se as acçőes e omissões que ordena são realmente condições de vida e desenvolvimento do individuo e da sociedade, isto é, precisa conhecer as leis a que está subordinado o homem, individual e socialmente estudado. Isso não exclúe uma certa variedade de tractamentos juridicos, exigida pela diversidade das condições suciaes, assim como o facto de estarem as plantas e os animaes sujeitos a certas leis biologicas fundamentaes não exclúe a variedade de tractamentos agronomicos e zootechnicos, diversidade imposta pelas differenças de clima e de meio cosmico em geral.

Mas, dir-se-ha, qual o processo logico que nos dará o conhecimento das leis a que estão subordinados o individuo e a sociedade, leis que devem constituir o conteúdo das normas juridicas? O unico por meio do qual se descobrem toulas as verdades scientificas, a combinação do methodo inductivo com o deductivo. A observação, directa e indirecta (ou por meio da historia), do que se tem passado em todos os pontos do espaço e do tempo que nos é dado conhecer, leva-nos a induzir, isto é, a, partindo do particular, chegar a esta verdade geral: o homem só vive e desenvolve-se na sociedade; a sociedade é um meio necessario ao 
homem, assim como é um meio imposto a certos animaes pela natureza destes. Os animaes gregarios organisam as suas sociedades instinctivamente, natural $e$ necessariamente. A observação da natureza individual do homem, o conhecimento dos seus attributos physicos e psychicos, isto é, das leis a que está sujeito o homem, ou do que ha de constante, de geral, de invariavel, no homem, comprova a verdade enunciada, porquanto do conhecimento da natureza humana deduzimos, como natural consequencia, a necessidade da vida social. $\mathrm{O}$ estudo das sociedades, quer de homens - quer de animaes, auctorisa esta outra generalisação: a sociedade só é possivel, restringindo cada um dos consociados sua actividade. Tão necessaria é esta restricção da actividade, que o proprio instincto a impõe ans animaes. As abelhas, os castores e as formigas, vivem em sociedade, porque cada um dos membros da communhão se mantém dentro de uma certa esphera de actividade, e respeita a actividade dos outros consociados

A mesma necessidade, ineluctavel e evidente, de restingir a actividade individual, é imposta ao honmem, que, capaz de raciocinar e generalisar, comprehende essas duas verdades fundamentaes, e, tendo a vontade impellida por idéas e sentimentos, é levado a fazer o que reconhece necessario para se conservar e desenvolver.

Essas duas leis fundamentaes, de ordem sociologica, constitúem uma solida base scientifica para o direito. Todo o conjuncto das normas juridicas nada mais é que um systema de limitações impostas pela necessidade da vida em communhão ao campo de actividade de cada individuo, e consequentemente, por outro aspecto, um systema de faculdades em que se declara o que a cada um é licito fazer, ou deixar de fazer. Todas as instituições juridicas são deduzidas do prin cipio da restricção da actividade individual, condição sine qua non da vida social. No direito das cousas, o 
legislador estabelece uma série de restriçcões á actividade individual, no uso e goso das cousas materiaes de que precisa o homem para subsistir e desenvolverse. Nas leis sobre contractos, reconhecendo a necessidade, incessantemente crescente com a civilisação, das permutas de cousas e serviços, o legislador crêa certas restricções á liberdade de agir, isto é, impõe certas obrigações, sem as quaes os contractos não desempenhariam a sua funcção indispensavel. Nas relações de familia, ainda o direito é um systema de restricções á actividade individual, em beneficio da sociedade no presente e no futuro. O exame de todas as instituições mostra que a disciplina juridica tem por missão traçar e manter uma linha divisoria entre os membros da sociedade, para que cada um se conserve e desenvolva, sem impedir a conservação e desenvolvimento dos demais consociados.

Isto posto, temos que, sendo o homem um ser necessariamente impellido por sua natureza á vida social, a necessidade de limitar a actividade dos individuos, e dos varios agrupamentos sociaes formados por estes, se lhe impõe de modo ineluctavel. Essa limitação da actividade é uma condição primordial de vida para a sociedade, e consequentemente tambem para $o$ individuo. Para que a sociedade se conserve e desenvolva, é imprescindivel que cada individuo, ou cada uma das entidades collectivas que se formam no seio da sociedade, tenha uma esphera de acção, dentro da qual realise tudo o que lhe é condição de vida e desenvolvimento, sem impedir os consociados, ou as outras collectividades, de se conservarem e desenvolverem.

Ahi está o principio fundamental do direito. As normas juridicas nada mais são do que regras de conducta, cujo conteúdo se nos depara nas deduções dessa verdade geral. Queremos saber se um acto deve, ou não, ser permittido pelo legislador: nada mais nos cumpre fazer do que indagar se a pratica desse acto é 
para o homem uma condição de vida e desenvolvimento, cuja realisação não obsta a que seus semelhantes egualmente se conservem e desenvolvam.

$O$ principio fundamental assignalado é a maior do syllogismo. A menor nos é dada pelo estudo da natureza do individuo e da sociedade. Aqui apparece a necessidade de conhecer as diversas sciencias que estudam o homem individualmente e a sociedade, isto é, a anthropologia e as sciencias sociaes particulares. $O$ homem não póde viver sem se alimentar, sem se vestir e sem se abrigar contra as inclemencias do tempo. Todos estes actos pódem ser praticados pelo individuo, sem que os demais membros da mesma sociedade sejam tolhidos na pratica de actos eguaes. Dahi uma serie de normas de conducta, que garantem a posse, o uso e o goso das cousas materiaes, indispensaveis á satisfacção dessas necessidades. A sociedade e o individuo não se pódem desenvolver sem a permuta de cousas physicas e de serviços. Consequentemente, formulemos regras que determinem o modo de permutar os serviços e as cousas, traçando em torno de cada individuo a necessaria esphera de actividade, sem prejuizo da liberdade egual de seus semelhantes. Tão complexa é a vida social, que nem sempre podemos verificar com facilidade se a pratica de um acto deve, ou nāo, ser permittida, ordenada ou prohibida. A antropologia e as sciencias sociaes ainda não se acham tão desenvolvidas, que sempre nos apresentem com segurança a menor de que carecemos para a conclusão. Um exemplo: o regimen quiritario da propriedade, regimen ainda hoje consagrado pelas nações cultas, é o que se conforma com a natureza da sociedacle, ou cumpre adoptar o regimen collectivista? A renhida controversia dos economistas ainda não chegou a uma solução, que se imponha como verdade scientifica incontestavel. Ainda no conceito de muitos cultores da economia politica o collectivismo seria um systema de 
perniciosas consequencias para o desenvolvimento social. Isso mostra quanto é difficil descobrir a verdade, conhecer a lei scientifica, a que o legislador deve dar a forma de norma juridica, auxiliando a sancção natural (a connexão das consequencias com os factos) com a sancçáo physica do Estado. O conteúdo da norma juridica deve ser sempre uma verdade scientifica, uma condição de vida e desenvolvimento da sociedade e do individuo, dada pela inducção, ou deduzida de uma verdade superior

Mas, dir-se-ha, Ihering demonstra "que isso não se tem verificado, o estudo da historia do direito nos leva á convicção de que realmente o conteúdo do direito tem variado ao sabor dos interesses de cada povo e de cada épocha. Tem-se prohibido em um periodo historico o que em outro se ordena. Não o contestamos, pois seria negar a evidencia. Mas a conclusão que decorre do facto estudado em face das verdades conhecidas é que a extrema difficuldade de apprehender as leis a que estão sujeitos o individuo e a sociedade, tem impedido de formular normas juridicas baseadas em leis verdadeiras. $E^{\prime}$ o que se tem dado com todas as sciencias. Quando os legisladores reputavam a escravidão uma instituição legitima, isto é, uma condição de desenvolvimento para a sociedade, quando prohibiam com o maximo rigor a adopção de um culto religioso differente do do Estado, quando suffocavam a liberdade da consciencia e a do pensamento, quantos erros, egualmente graves, não eram sustentados convictamente pelos astronomos, pelos physicos, pelos chimicos! Quem, jámais, do facto de terem os astronomos sustentado o erro geocentrico tirou a conclusão absurda de que a astronomia não é uma sciencia? Quem da grosseira concepção dos quatro elementos, a terra, a agua, o ar e o fogo, dominante na antiguidade, deduzio qualquer argumento contra a existencia da chimica? Se essas sciencias, muito mais faceis que 
o direito, porquanto os phenomenos de que se occupam são muito mais simples, ou muito menos com. plexos, foram a pouco e pouco e penosamente descobrindo as suas verdades, que ha de extranhavel nas theorias erroneas acceitas pelos legisladores como a expressão da verdade? Como não consagrar a escravidão, quando um genio e um sabio da estatúra de Aristotelis, o iniciador do methodo positivo, affirmava convictamente que ha homens destinados pela natureza a ser escravos?

O conteúdo dã norma juridica não é o interesse variavel, ou o opportuno, como diz Ihering. O que Ihering denomina opportunidade consolidada pela experiencia é uma verdade juridica geralmente acceita. $O$ con. teúdo da sciencia do direito, que é a base da arte do direito, é a verdade. Pela inducção e pela deducçáo verificamos que a pratica, ou a abstenção, de um certo acto produz consequencias perniciosas para a sociedade, consequencias perniciosas que são a sanç̧ão natural da conducta humana: eis ahi uma verdade scientifica. Como nem todos comprehendem a verdade descoberta, e os proprios individuos que a comprehendem, como bem diz Ihering, são levalos a um procedimento con. trario, por fraqueza ou perversidade, o Estado dá a fórma de preceito, regra, mandamento ou norma de conducta. á lei scientifica, e á sanção natural accrescenta a sua sancção artificial, a coacção social. Se a sociedade rectifica o seu conceito, averigúa que uma norma juridica ordena a pratica de um acto que a experiencia prova ser contrario ás suas condiçōes de vida e desenvolvimento, dá o envolucro legal á nova verdade descoberta. Em meio das affirmações do direitos discutidas ou contestadas - quantas verdades não possuimos já, superiores a qualquer controversia? A liberdade de locomoção, a egualdade juridica, a liberdade de consciencia, a de pensamento, o direito de dignidade, o de associação, a união conjugal monoga- 
mica, o direito de punir, e tantos e tantos outros, traduzem verdades scientificas sobre as quaes ha pleno accordo entre os homens sensatos. Reconhecem todos a necessidade da pratica dos actos e das omissões que os legisladores consagram nas normas juridicas concernentes a essas materias. Concebe-se uma sociedade, cujo progresso dependa da suppressão da liberdade de locomoção para os seus membros em geral? Depois de sabermos que anthropologicamente os homens são todos eguaes, que em todos ha os mesmos attributos fundamentaes, somaticos e psychicos, como poderemos admittir a desegualdade juridica? Que homem sensato ousaria negar a necessidade das penas, para evitar a reproducção dos factos que importam offensas graves á sociedade? Nem se diga com Ihering que a sociedade hoje considera crime o que amanhã permitte como acto innocente; que a edade media punia com as mais graves penas os magicos e as feiticeiras, quando hoje seria ridiculo estabalecer qualquer tratamento juridico especial para esssas pessoas; e que isso prova que o direito è completamente extranho á verdade. Já respondemos á observação: as graves penas comminadas na edade media a delictos irrisorios, que se reputavam gravissimos attentados contra a ordem social, significam simplesmente desvios da verdade, erros de apreciação, preconceitos, ignorancia das verdaleiras condições de vida e desenvolvimento da sociedade.

$\mathrm{Na}$ theoria de Ihering não ha logar para um direito ideal. O direito positivo nasce da lucta dos interesses. Entre direito e verdade nada ha de commum. O que cletermina a promulgação de uma nova regra de di. reito é o apparecimento de um novo e momentaneo interesse. Ainda neste ponto o ensinamento de Ihering não se conforma com os factos. Constantemente vemos condemnada pela opinião dos competentes uma instituição, ou preconisada a necessidade de promul. 
gar normas juridicas sobre uma série de actos que escápam á sancção do direito. Nada mais commum do que julgar uma sociedade que certas leis precisam ser reformadas. Qual o criterio que nos guia ao formarmos esses conceitos? E' a observação dos resultados colhidos da applicação de um dado instituto juridico que nos revela que o legislador, ao promulgar a lei, não apprehendeo uma necessidade social; ou a deducçào de uma verdade scientifica do dominio da anthropologia, ou das sciencias sociaes particulares, que mostra que uma condição de vida e desenvolvimento social carece de ser assegurada pela coacção social. Tambem a sociedade se modifica. Como organismo, ou ser vivo, que é, passa por uma constante evolução, e a cada periodo de seu desenvolvimento se liga uma série de recessidades peculiares. Assim, ao lado das necessidades communs a todos os organismos sociaes, constantes, permanentes, ha outras proprias de cada phase social, o que faz que ao lado dos principios e das normas juridicas universaes e immutaveis haja instituições variaveis. Nem se diga haver contradiç̧ão entre esta verdade e o conceito de que o direito é um conjuncto de leis scientificas, que servem de base á formulação das normas juridicas. O homem physiologicamente está sujeito a leis immutaveis, e a leis peculiares a cada edade. A alimentação da infancia não é a da velhice. A hygiene da juventude não é a da decrepitude.

As verdades que aqui ficam expostas são a cada momento implicitamente reconhecidas pelos adeptos de todas as escólas. O sectario da escóla theologica, quando coherente, orthodoxo, architecta todo o edificio do direito sobre os alicerces fornecidos pela revelaçá; mas, quando observa a infracção de uma lei destinada a assegurar uma das condições primordiaes da existencia social, ou a promulgação de uma norma juridica que attenta contra essas condiçoes, exclama: onde 
irá parar a sociedade, se as cousas continúam assim? $\mathrm{O}$ racionalista harmonico entende que todo o direito não passa de um desenvolvimento, ou antes applicação, do principio do justo, dado pela rasão como faculdade intuitiva; mas, quando se lhe depara uma dessas inversőes da ordem social, que pōem em perigo a vida collectiva, por sua vez appella para o instincto de conservaçáo individual e social, como o mais poderoso argumento contra o abuso perpetrado. No amago de todas as doutrinas philosophico-juridicas está o reconhecimento implicito de que o direito nada mais faz do que formular normas de conducta cujo conteúdo é, ou deve ser, uma verdade scientifica, o conhecimento de uma condição de vida ou de desenvolvimento da sociedade.

Se na realidade a missão do direito consiste em, verificada uma condição de vida e desenvolvinıento da sociedade, dar-lhe a forma de norma de conducta e assegurar-lhe a realisação pela coaç̧ão do Estado, e se o processo de que dispomos para conhecer as condiçóes de vida e desenvolvimento da sociedade se reduz ao methodo positivo, á inducção, e á deducção, porque náo havemos de acceitar a doutrina que systematisa as verdades implicitamente reconhecidas por todas as outras escólas? Quer-se saber qual a edade em que a norma juridica deve permittir o casamento. A resposta de todas as demais escólas não tem a precisão da que nos offerece a theoria scientifica do direito, a qual nos manda consultar a physiologia, parte da antropologia, que estuda os phenomenos da vida e as funç̧ões dos orgams. Tem o legislador de fixar a substancia de que se deve fazer a moeda. Cumpre-lhe indagar o que ensina a respeito a econo. mia politica. E' mister promulgar uma constituição para um povo. Antes de fazel-o, incumbe ao legislador constituinte examinar a historia politica dos povos, e apurar qual a organisação do poder publico que 
mais efficazmente tem garantido a liberdade, a ordem e o progresso. E assim por deante.

A formulação das normas juridicas não é uma tarefa do empirismo, mas um trabalho scientifico. Não basta pesquisar isoladamente, e no momento de formular cada norma, ou de crear cada instituição juridica, as verdades particulares que devem servir de molde á regra de direito. Importa elevar-se aos principios, ás verdades geraes fundamentaes, espiritualisar a sciencia pela philosophia.

A escóla de Ihering nos offerece exactamente o contrario de tudo isso. Adoptando o methodo teleologico, que só nos ensina a adaptar os meios aos fins, o notavel jurisconsulto seguio um processo que nada tem de commum com o methodo scientifico. Quereria Ihering constituir uma sciencia pratica, ou applicada? As palavras sciencia pratica encerram idéas que se repellem. Não ha sciencia pratica. O que ha é scien. cia, e preceitos baseados na sciencia, isto é, arte. O homem se utilisa de noções scientificas, para formular normas de conducta que the sejam uteis na vida. Estudam-se todas as sciencias, desde a mathematica até ás sciencias sociaes, para das suas verdades geraes se deduzirem regras de applicação util. Sem o previo conhecimento das connexões causaes, das ligações necessarias dos effeitos com as causas, que regras artisticas poderiamos formar com segurança?

Este é o defeito capital da theoria empirica de Ihering: a norma juridica não assenta em principios, ou sequer leis scientificas derivadas. O direito se reduz a um simples meio de garantir interesses variaveis, e assim fica entregue aos erros, aos preceitos, ás paixões e aos interesses do legislador.

Dr. Pedro Lessa 